\title{
QUANDO A MAGREZA PASSA A SER CONSIDERADA UM IDEAL MASCULINO: UM OLHAR SOCIOANTROPOLÓGICO ACERCA DOS TRANSTORNOS ALIMENTARES EM HOMENS ${ }^{1}$
}

\author{
Bianca de Vasconcellos Sophia ${ }^{2}$
}

RESUMO: Este artigo discute o surgimento de casos de anorexia e bulimia em homens, e sua relação com: a - as questões socioculturais ligadas ao culto à magreza e seus desdobramentos (como a noção de estilo de vida); e b - as discussões sobre masculinidades, experiências corporais e subjetivas desses sujeitos. Seu principal objetivo é compreender como estes transtornos alimentares, tidos como distúrbios de ordem psiquiátrica pela literatura biomédica, não estão restritos somente ao feminino, sugerindo também implicações ligadas ao processo de elaboração do saber médico, seus campos de pesquisa e atuação. A metodologia empregada foi a realização de entrevistas via MSN Messenger, com 20 homens entre 13 e 30 anos, que declaram passar ou ter passado por algum tipo de experiência envolvendo a anorexia e/ou bulimia.

PALAVRAS-CHAVE: Gênero; transtornos alimentares; antropologia da saúde.

Recebido em: outubro de 2012 Aceito em: abril de 2013

Para citar este artigo:

SOPHIA, Bianca; Quando a magreza passa a ser considerada um ideal masculino: Um olhar socioantropológico acerca dos transtornos alimentares em homens. In: Revista Intratextos, 2013, vol 4, no1, p. 119-139. DOI: 10.12957/intratextos.2013.6225

\footnotetext{
${ }^{1}$ Este trabalho é fruto da pesquisa realizada em minha dissertação de mestrado no Programa de Pós-Graduação em Ciências Sociais da Universidade do Estado do Rio de Janeiro (PPCIS/UERJ).

${ }^{2}$ Doutoranda do Programa de Pós-Graduação em Ciências Sociais da Universidade do Estado do Rio de Janeiro (PPCIS/ UERJ). Bolsista Capes. Email: bvsophia@gmail.com
} 
Segundo o discurso biomédico, a anorexia e a bulimia são descritas como transtornos da imagem corporal que afetam diretamente o comportamento alimentar dos sujeitos. Associadas a este comportamento estão: as práticas de restrição parcial ou total da alimentação, o uso de medicamentos (emagrecedores, laxantes, diuréticos, ansiolíticos, etc.), a indução de vômito, a prática vigorosa de atividade física, entre outros. A adoção deste tipo de comportamento está relacionada a um "medo mórbido de engordar".

Entretanto, este "medo de engordar" é uma característica contemporânea que envolve motivações socioculturais distintas de outros períodos históricos, por exemplo: o jejum, o vômito autoinduzido e o uso de purgantes nos rituais religiosos do Egito antigo; os jejuns prolongados das "santas anoréxicas" na Idade Média; as dietas rigorosas de jovens e sua associação com os quadros de histeria no século XIX (CORDÁS; CLAUDINO, 2002).

Estas diferentes formas de entendimento não negam o caráter biológico desses transtornos alimentares, mas demonstram como os fatores contextuais são importantes na formulação de outros significados e simbolismos atribuídos a estas práticas. Um exemplo deste tipo de formulação pode ser observado nos trabalhos sobre o assunto no campo das ciências sociais, como a etnografia de Munson (1998) sobre o universo das aspirantes a modelo e manequim; os estudos de Lira (2006) e Sophia (2009) a respeito dos grupos prótranstornos alimentares na internet; a análise de Saccol (2009) sobre as representações dos profissionais de saúde.

Grande parte dos trabalhos mencionados utiliza como pano de fundo a questão do corpo magro como sinônimo de beleza na contemporaneidade. Nestas circunstâncias, estar de acordo com este modelo ideal de beleza representa ter um status superior àqueles que não estão nesta condição. Daí a noção de que a sociedade ocidental contemporânea possui valores "lipofóbicos" (de horror à gordura) dos quais podemos atribuir a uma espécie de lógica que relaciona este ideal de corpo aos sentimentos de felicidade e bem-estar.

No âmbito da saúde e da doença, estes valores atuariam através do discurso que associa a magreza à "vida saudável” e a obesidade à doença. Ser obeso ou estar acima do peso, não só significa se distanciar dos padrões corporais ideais, como também ser estigmatizado por reunir "fatores de risco" para o desenvolvimento de diversas doenças (diabetes, hipertenção, problemas cardíacos, etc.). 
Além disso, esta discussão demonstra o poder dado à biomedicina na cultura ocidental, modelo esse responsável pelas definições de doenças, especificações dos sintomas e formas de tratamento (LAPLANTINE, 2001). O discurso biomédico também orienta comportamentos, contribuindo na formulação de estilos de vida. No caso da anorexia e da bulimia, esta visão se restringe a produção de conhecimento sobre os tipos de tratamentos, sintomas ou alterações fisiológicas dos pacientes, deixando de lado outros questionamentos e posições a respeito, como os argumentos defendidos em outros campos disciplinares e os discursos dos indivíduos pró-transtornos alimentares.

A valorização extrema da magreza leva pessoas de diversas partes do Brasil e do mundo a buscarem a internet com o intuito de compartilharem suas experiências. Estas pessoas estabelecem uma rede de apoio cuja ideia principal é difundir o "estilo Ana (anorexia) e Mia (bulimia) de ser". Neste contexto, a anorexia e a bulimia ganham outros significados, sendo transformadas em símbolos de exaltação. A Ana e a Mia representam figuras animadas, exemplos de persistência e controle do corpo. Ambas têm um poder ambíguo de proporcionar o bem-estar do sujeito através da "amizade" ou a amargura, caso o controle da comida ingerida e a perda de peso não sejam satisfatórios às metas estabelecidas por estes indivíduos.

Segundo Soares e Aragão (2006), o movimento pró-anorexia e pró-bulimia é um fenômeno que teve origem nos Estados Unidos e na Inglaterra por volta do ano 2000. No Brasil, estes grupos começaram a aparecer a partir de 2002 com os weblogs (diários virtuais), e foram potencializados com a criação das redes de relacionamentos do Orkut (2004). Os adeptos deste grupo costumam demonstrar o horror à gordura por meio de fotos de pessoas famosas, tabelas de contagem calórica, apresentação de dietas, entre outros recursos.

É comum observar nestes espaços frases, tais como: "O que me alimenta, me destrói”, "Gordos precisam de dietas e magros de Ana para a alma", "Perfeição não inclui comida", “Obesidade é horrível e gordos são inúteis, lembre-se disso!”, “A sociedade te discrimina porque você é gordo, depois ficam chocados se você morre de fome", etc.

Em meio a esta discussão, a questão de gênero emerge como um elemento problemático, na medida em que boa parte da literatura médica sobre transtornos alimentares associa o desenvolvimento da anorexia e da bulimia às mulheres jovens. A preocupação com o peso corporal seria uma característica do feminino por estar atrelada a uma performance de gênero que reforça a crença de que a mulher necessita ser magra, bem-sucedida, saudável e 
satisfeita por ter um corpo que personifique o belo como objeto de sedução ou gozo do outro (MORGAN; VECCHIATTI; NEGRÃO, 2002; MOTTA, 2007).

Dentro desta lógica, a visão biomédica acaba agregando valores essencialistas e dicotômicos que embasam a diferenciação entre homens e mulheres, bem como a questão relacionada à orientação sexual. Isso é explicado a partir da noção de que as mulheres heterossexuais e os homossexuais são entendidos como "grupos de risco" para transtornos alimentares, pois tenderiam a se preocupar mais com a aparência física do que os homens heterossexuais e as lésbicas. Tal discurso recorre até mesmo à neurociência para explicar a presença do desenvolvimento de "aptidões femininas" no cérebro de um homossexual (CARLAT; CAMARGO JR; HERZOG, 1997); além dos hormônios para sustentar a ideia de que os homens com anorexia nervosa podem apresentar queda dos níveis de testosterona e redução do volume testicular, ocasionando a diminuição do desejo e desempenho sexual (ou seja, diminuição dos traços "masculinos"). Esta noção é importante, no sentido de que é construída a partir de concepções culturais de gênero em que a atividade sexual representa uma das principais formas de manifestação do masculino.

Existem ainda situações descritas pela biomedicina em que os homens podem desenvolver tal comportamento como uma forma de otimização das aptidões físicas, por exemplo, os atletas, bailarinos, soldados, modelos e outros profissionais. Além disso, os transtornos alimentares em homens estariam relacionados ao abuso substâncias que alteram a percepção da realidade, como o álcool, as drogas e os medicamentos; e também a históricos de depressão e transtornos de personalidade.

Outro aspecto relevante está na falta de estudos sobre a temática. Entre os motivos estão: o número reduzido de casos (aproximadamente, um homem em cada dez casos de transtornos alimentares em mulheres) e a baixa procura dos homens por tratamento médico.

Tais justificativas não consideram o modo como são formuladas culturalmente as concepções de homem nem o peso das explicações científicas na disseminação de discursos e verdades; além de não examinarem como estes elementos são absorvidos pelo campo institucional, responsável pela elaboração de políticas de saúde.

Sendo assim, este artigo ${ }^{3}$ pretende discutir como os pressupostos culturais atuariam em

\footnotetext{
${ }^{3}$ Esta pesquisa foi submetida e aprovada pelo Comitê de Ética em Pesquisa do Instituto de Medicina Social da Universidade do Estado do Rio de Janeiro, CEP/IMS/UERJ (CAA - 3145.0.000.259-10).
} 
diversos campos da vida social e individual, formulando discursos, relações de poder, comportamentos, estados físicos e mentais.

\section{Campo na internet}

A proposta inicial deste trabalho era entrevistar homens com diagnóstico de anorexia e/ou bulimia que estivessem em tratamento em um ambulatório ou grupo de apoio para transtornos alimentares na cidade do Rio de Janeiro. Entretanto, após algumas semanas de contato com professores, pesquisadores (médicos, psicólogos, nutricionistas, etc.) e colaboradores destes locais, foi constatado que seria inviável acessar o grupo pesquisado por meio institucional, tendo em vista a escassez de homens como pacientes, e por se tratar de um estudo na área de ciências sociais.

A opção foi retornar ao campo dos grupos pró-anorexia e pró-bulimia utilizando a Internet como ferramenta de acesso a população do estudo, visto que a presença de homens neste ambiente já havia sido observada (SOPHIA, 2009).

A princípio a ideia era entrar em contato com estes sujeitos pela Internet e realizar as entrevistas através de um encontro face a face. Para facilitar o acesso aos entrevistados e delimitar a população de estudo, foi feito um levantamento de algumas comunidades do Orkut sobre o assunto e de seus participantes com o perfil "masculino" (nome e foto) que tivessem registrado a cidade do Rio de Janeiro como suposto local de origem/residência.

Não foi descartada a possibilidade de entrevistar os participantes pelo computador, por meio do MSN Messenger ou outro tipo de local "virtual" que permitisse uma comunicação sincrônica. Este recurso seria utilizado em último caso.

Ao longo do trabalho de campo, tal questão precisou ser revista, na medida em que o fato de restringir o campo de estudo buscando entrevistar pessoalmente ou pela web homens que participam destes grupos e que moram no Rio de Janeiro demonstrou-se limitado por diversos motivos. Alguns perfis não possuíam local de origem ou apresentavam locais fictícios, como "obesolândia". Outra questão foi a grande presença de pessoas que residiam em outros estados do Brasil (São Paulo, Minas Gerais, Paraná, Amazonas, etc.). 
Percebeu-se então, que a estratégia de limitar o campo em apenas uma cidade brasileira não levava em consideração as reflexões sobre o espaço "virtual" - considerado um ambiente em que pessoas de diferentes partes do país e do mundo costumam transitar com mais facilidade ao se conectarem ao computador, ao telefone e a outras tecnologias que permitem o acesso à rede -, nem explorava suas possibilidades.

Com isso, este trabalho foi desenvolvido através de um processo de adaptações e incorporações de elementos, levando em consideração a própria especificidade do campo e os preceitos éticos da Resolução ${ }^{0}$ 196, de 10 de outubro de 1996, que aponta as diretrizes e normas regulamentadoras de pesquisas envolvendo seres humanos ${ }^{4}$.

Foram entrevistados 20 rapazes/homens entre 13 e 30 anos que declararam passar ou ter passado por algum tipo de experiência relacionada à anorexia e à bulimia. Contudo, esta experiência pode ter sido ou não diagnosticada e tratada por profissionais de saúde.

\section{"Ao contrário da maioria dos homens, que querem mais músculos, eu gosto de ficar magrinho" 5}

O trecho que abre esta seção resume boa parte dos elementos que foram observados nos relatos dos entrevistados, bem como aponta alguns aspectos discutidos anteriormente. Este fragmento demonstra a tensão existente entre os significados atrelados ao modelo hegemônico de corpo masculino, caracterizado em nossa cultura pela figura do homem com músculos desenvolvidos, e um formato corporal que foge desse padrão, representado pelo homem magro.

Por ser um conteúdo exposto em um perfil do Orkut que se conecta a uma rede de pessoas e de comunidades sobre o assunto, de alguma maneira esta informação é compartilhada e difundida, caracterizando assim, outras formas de entendimento e de significados atribuídos a uma categoria de origem biomédica, como os transtornos alimentares.

\footnotetext{
${ }^{4}$ Esta pesquisa foi submetida ao Comitê de Ética em Pesquisa do Instituto de Medicina Social (CEP/ IMS) da Universidade do Estado do Rio de Janeiro (UERJ) (CAA - 3145.0.000.259-10).

${ }^{5}$ Frase retirada de um dos perfis visitados.
} 
Estas experiências são diversificadas por conta da própria história de vida de cada entrevistado. No entanto, grande parte dos relatos possue algo em comum, como a vontade incessante de se estar "bem”, de não se sentir excluído ou rechaçado socialmente pela sua aparência corporal.

A preocupação excessiva de alguns homens com a aparência física, especialmente com o corpo isento de gordura e sem músculos desenvolvidos, é um exemplo que diverge de um tipo de forma física considerada masculina. Ninguém estranharia se encontrássemos um homem numa academia de ginástica fazendo exercícios que desenvolvam as regiões superiores do corpo (ombros, braços e peitoral) comumente ligadas a um ideal estético e aos aspectos simbólicos de força e virilidade atrelados à masculinidade (SABINO, 2000).

Este comportamento é visto como algo que reforça as construções sociais a respeito da masculinidade hegemônica, principalmente aquelas que acreditam numa causa orgânica, numa suposta essência ou natureza do homem. De acordo com esta visão, o corpo esbelto estaria associado às mulheres, aos homossexuais e aos bissexuais masculinos, tendo em vista a noção de que são grupos que costumam se preocupar mais com o formato corporal do que os homens heterossexuais e as lésbicas por apresentarem uma relação com a essência feminina (CARLAT; CAMARGO JR.; HERZOG, 1997).

Entretanto, os estudos sobre masculinidade irão apresentar a ideia da existência do homem no plural, isto é, a presença de modelos de masculinidades que interagem entre si e com o padrão hegemônico (CONNELL, 1995; KIMMEL; MESSENER, 1998). Estas variações são dinâmicas e contextuais. Isto permite, enquanto formulação teórica, uma articulação com a questão do excesso de cuidado de alguns homens com a aparência física na contemporaneidade, a chamada "metrossexualidade".

Ao transportamos estas reflexões para a análise dos relatos dos entrevistados, veremos que a preocupação com a forma física é algo bastante citado. Isso demonstra como o discurso lipofóbico não só afeta as mulheres como também os homens.

Quando indagados sobre a percepção da própria aparência física e do sentimento de satisfação com ela, todos os entrevistados demonstraram insatisfação. A inquietação com a gordura corporal era claramente expressa. Porém, esta gordura está concentrada especialmente na região abdominal. 
De acordo com o discurso médico, o excesso de gordura no abdome não apenas costuma ser um indicador de que o indivíduo está acima do peso como ainda representa uma tendência para o desenvolvimento de doenças cardiovasculares e o diabetes (DAVIES, 1999; CONRAD, 2007). Por outro lado, este aumento da gordura corporal também representa o distanciamento do padrão estético tido como ideal em nossa sociedade. Não por acaso a menção de cirurgias de retirada de gordura localizada, como a famosa lipoaspiração, como um tratamento imediato e eficaz na redução de medidas.

Pesquisadora: Você mudaria alguma coisa em seu corpo?

Barriga. Acho flácida. (B - 25 anos)

Cirurgia para gordura localizada na região do abdome. Depois que emagreci fiquei com um pouco de barriga e, mesmo indo para academia, ela não some! (I - 20 anos)

Barriga. Na verdade, do pesco para baixo até a cintura. ( $\mathrm{P}-20$ anos)

$\mathrm{Na}$ contemporaneidade, a popularização das cirurgias plásticas e dos tratamentos estéticos se apresenta como uma medida eficaz na retirada da gordura indesejada e na modificação dos traços percebidos como "imperfeições corporais". Estas técnicas advindas da área biomédica ganham novos significados, passando para uma condição "quase moral" e fornecendo critérios de avaliação individual em que a obtenção da melhor forma física, da jovialidade e da longevidade são almejadas (ORTEGA, 2003).

Os aspectos citados são apropriados pelos discursos dos entrevistados, como mecanismos de mudança de uma condição corporal. Como se ao fazerem uma cirurgia plástica ou tratamento estético, eles pudessem "nascer de novo", mudar de status (MELO, 2004) ou alcançar a "felicidade".

Tais questões nos remetem às análises de Mary Douglas (1976) e Robert Hertz (1980) sobre os aspectos simbólicos responsáveis por categorizações, distinções sociais e interdições ao corpo. Estas concepções são aplicadas ao tema, tendo em vista que a gordura é apresentada como uma impureza presente no corpo que necessita ser expurgada e evitada. Deste modo, a gordura atuaria como um fator de distinção social, no sentido de que somos classificados pelo nível de gordura corporal e, portanto, podemos ser estigmatizados por não estarmos enquadrados nos padrões aceitáveis de beleza e saúde. 
Outros recursos utilizados para o controle do peso e do formato corporal, que também podem ser observados nos relatos analisados, são as dietas e os exercícios físicos. Estas práticas nem sempre estão atreladas ao discurso de vida "saudável" pregado pela biomedicina, mas buscam a tão sonhada "boa forma".

Pesquisadora: O que você faz para cuidar da sua aparência física?

Dietas, muitas mesmo! Conto as calorias sempre, bebo mais de 2 litros de água e também faço aeróbica em casa quando posso. [...] Já fiz dietas bem restritas, como a da bolacha água e sal com um copo de água. Dieta da sopa de missô. Dieta do shake e dieta das frutas entre outras. (O - 23 anos)

Já não como há 3 dias, vivo apenas de água. Estou em uma dieta nova que vi em um filme. Sabe, não como nada e quando sinto que vou desmaiar como um derivado do leite (queijo, por exemplo). [Pesquisadora: Qual filme?] Um filme atípico, "O diabo veste prada". Uma cena da Emily [em que] ela diz ter emagrecido muito com esta dieta. (Retirado de uma conversa informal com um dos contatados)

Estas formas de controle do corpo estão intimamente atreladas a um processo de individualização que ganha destaque no mundo contemporâneo. Nestas circunstancias, o sentir-se gordo ou feio pode ser entendido à luz dos estados de desconforto e vergonha discutidos por Elias (1990). Estes sentimentos representam uma reação à infração de uma regra social (o ato de comer demasiadamente ou não comer adequadamente, por exemplo) ou a censura causada pelo olhar do outro (que pode ser imaginário) sobre seu comportamento (ou sua aparência física).

Bourdieu define habitus como uma matriz responsável pela criação de comportamentos, visões de mundo, práticas ou posturas corporais que são internalizadas ao longo de um processo incessante de formação dos indivíduos na sociedade (BOURDIEU, 2000). O habitus distingue pessoas, demonstra hierarquias e valores que são mais privilegiados do que os outros, como no caso dos que se aproximam do ideal de corpo e de saúde. Instaura-se o que Miskolci (2006) chama de "dicotomia da inclusão e exclusão", que também se reflete na subjetividade e na história de vida dos sujeitos. Estas questões podem ser vistas nos relatos de alguns dos entrevistados acerca de suas experiências envolvendo a aparência física, suas práticas e o convívio social.

Trabalhava em hotel 5 estrelas. A dona escolhia a dedo seus funcionários e com o tempo fui sentindo a pressão do sobrepeso [...]. Os meios que frequento exigem uma boa aparência e eu me policio muito quanto a isso. (Retirado de uma conversa informal com um dos contatados) 
Me sentia mal, excluído. Queria ser diferente do que era! Chorava muito e me excluía! [...] Me lembro de uma vez que eu não pude participar de uma gincana escolar.. tipo um teatro (que eu adorava) e não pude porque era gordinho. A professora não me deu o papel mesmo sabendo que eu era ótimo no teatro. Aquilo me marcou muito! (B - 25 anos)

Me sentia mal, triste, deprimido. Não gostava de sair, só queria ficar em casa. [...] Lembro de quando eu ia nas lojas comprar roupa e a atendente me olhava com uma cara [do] tipo: A roupa é para você? Vou ver se tem do teu tamanho. Ou até mesmo em relacionamentos as pessoas diziam que me adoravam, que eu era legal, mas não queriam nada comigo. Eu penso porque era por eu seu ser gordo. (I - 21 anos)

[...] Eu me sinto uma pessoa só. Eu tenho muitos amigos,[...] mas ao mesmo tempo não tenho. [...] Quando eu ando, sinto como se estivesse um holofote em cima de mim. Me sinto em meio a uma sala lotada, gritando pelos pulmões e sem ninguém sequer me ouvir, me ajudar! [...] As pessoas falam muito mal, mas ninguém sabe o que sinto. Se faço amizade acham que é por interesse. Eu não sei o que eu vim fazer nesse mundo [...]. Não sei mesmo! Aí eu me sinto muito gordo, pesando $50 \mathrm{~kg}$, meus lábios chegam a ficar tão pálidos, parecendo que eu não tenho sangue algum. E eu opto, para isso, colocar o dedo na garganta e vomitar. (Retirado de uma conversa informal com um dos contatados)

Esta forma de lidar com quem não se enquadra nos padrões de corpo, de saúde e de comportamento ocasiona um sentimento de fracasso pessoal em que os indivíduos passam a ser vistos como responsáveis pelos seus hábitos e estilos de vida (ORTEGA, 2003). Segundo esta ideia, os indivíduos se veem "obrigados" a se conformarem com a norma como uma maneira de se esconderem ou escaparem da tirania da aparência e de uma suposta normalidade. Estar conforme os padrões representa uma tentativa de se proteger da estigmatização social. Daí a utilização de técnicas ascéticas como um mecanismo disciplinar, de controle do corpo e de configuração das subjetividades. Neste sistema, o sujeito necessita se autocontrolar, se autovigiar, se autopunir ou se autodestruir por conta do medo da rejeição (MISKOLCI, 2006).

Quanto à relação dos familiares, amigos e colegas neste processo, estas pessoas teriam um papel de acentuação ou de abrandamento no modo como os sujeitos se enxergam e desenvolvem suas práticas. Esta pessoas podem apoiar as práticas "ana" e "mia", podem demonstrar preocupação em ajudar no processo terapêutico, podem não desconfiar do comportamento adotado, podem fazer brincadeiras de mau gosto ou "fingir" não saber deste dilema.

Minha mãe sabe, mas não quer acreditar. Fica tentando amenizar e tal. (G - 17 anos)

No começo escondi dos meus familiares. Eu comecei a fazer isso por influência de amigos [...]. Comecei a andar com um grupo de pessoas que tinha o hábito de após as refeições vomitar. Para eles era mais uma brincadeira porque víamos vídeos, fotos de modelos e queríamos ser iguais a elas. Queríamos ser magros, bonitos, elegantes. 
Muitos faziam isso para manter o corpo. Me disseram para tentar, que eu ia gostar dos resultados e [que] dá para parar por vontade própria. Foi quando eu comecei a fazer também. No começo achei [uma] loucura vomitar para emagrecer, achei que não ia dar certo. Mas com o tempo eu fui me acostumando [...] e comecei a fazer constantemente. Achava aquilo normal. (I - 21 anos)

Eu simplesmente me isolava de todos. Não concordava, pois eu sofria de uma doença e eles faziam chacota disso... que era uma bobagem o que eu fazia e isso não me ajudaria em nada. (L - 18 anos)

A família reprovava tudo o que eu fazia em relação a beleza e a perda de peso. Alguns amigos e colegas de trabalho achavam bonito e me apoiavam, já outros tinham o mesmo comportamento que o da minha família. (S - 19 anos)

\section{Como os participantes desta pesquisa foram encontrados em comunidades da Internet} sobre o assunto e alguns trabalhos acerca destes espaços apontam para a formação de grupos de ajuda mútua que difundem um estilo de vida pautado na exaltação da magreza (LIRA, 2006; SOARES E ARAGÃO, 2006; SOPHIA, 2009), foram incluídas perguntas sobre a participação do entrevistado nestes locais, o relacionamento com seus membros e com sujeitos (num contexto off-line) que são a favor destas práticas. Este incorporação teve o intuito de compreender as motivações para a entrada desses sujeitos nas comunidades, de como são as formas de interação entre eles (dentro e fora destes ambientes) e que tipo de informações são trocadas e discutidas. Os entrevistados relataram:

Minha participação no começo foi para conhecer mais as pessoas, porque na minha família todos acham que sou maluco. Então, tenho com quem conversar e tal. Aí fui tentar ajuda lá. [Pesquisadora: Que tipo de ajuda? Poderia descrevê-la?] Saber se é normal as coisas que sinto, a forma que me enxergo. [P: Você conhece pessoalmente pessoas pró-anorexia e pró-bulimia?] Mais ou menos. Conheço mais dizem que não. [P: O você acha disso?] Eu penso que um deve apoiar o outro de uma forma positiva, só que nem todos pensam assim. Claro que tenho meu momento e entro em crise. Entendo essas pessoas, mas a vontade é de ajudar... [o] mais difícil é me ajudar. [...] O ruim destas comunidades [é] que tem pessoas para ajudar e prejudicar. Tem pessoas que dão dicas. [P: Que tipo de dicas?] Se você quer emagrecer... um cream cracker no café da manhã, um no almoço e um no jantar. Se sentir que está desmaiando coma duas azeitonas. [P: O que você acha disso?] Eu não acho legal, mas já fiz [...] não faço mais. [P: O que você costumava fazer?] O mais natural para mim era comer e segundos correr para vomitar. Já comi algodão, já comi amendoim com gengibre. [P: Onde você costumava se informar sobre isso?] Nas comunidades. Tem uma comunidade que acho que se chama 'quero pesar 46kg'. (A - 27 anos)

Só entro para pegar dietas e, às vezes, troco experiências. Mas só entro quando estou muito mal (gordo). [P: Que tipo de dietas?] Tipo, antes de me associar a comunidades pró-ana e pró-mia eu fazia até 10 dias de NF [no food, jejum] tranquilo. Depois, sei lá, descontrolei. Acho que é psicológico. Vi a possibilidade de fazer LF [low food, ingestão de pouca comida], ai gamei. Hoje em dia, vivo a base de chás e bolacha integral, exceto quando minha mãe me força a comer. Aí volto para a mia, mas me sinto muito mal quando vomito. [P: Você conhece pessoalmente pessoas pró-ana e mia?] Sim. O ajudo muito, o escuto muito. Ele é muito magro, passa mal e tudo de NF. (G - 17 anos) 
[P: Como é sua participação nas comunidades pró-anorexia e pró-bulimia?] Eu nem vejo. Só participo porque acho legal algumas, mas nem visito. [P: Você conhece pessoalmente pessoas pró-ana e mia?] Sim, muitas, principalmente minha prima e 3 amigos [...].[P: Vocês costumam trocar informações? Que tipo?] Sim. Todos os tipos. Saímos juntos também. Mas não falamos só de anas e mias, trocamos dicas um com os outros para não ficarmos obesos inúteis. [P: Poderia descrevê-las?] Tem muitas. Beber água gelada de 1 em 1 hora; tomar uma colher de vinagre toda manhã; se manter o dia inteiro de água e só ceder a alguns sucos (tipo de abacaxi e limão... somente de fruta que faz secar a gordura); quando sentir muita fome, mastigar um trident [chiclete] e se distrair com algo para a fome passar; quando sentir fome ao extremo, tomar um banho demorado e quente e depois ir dormir que passa, e muitas outras. [...] Tem amigos que usam cocaína para passar a fome, mas tenho medo de experimentar e virar um viciado. Por isso, não uso. Mas até minha prima diz que não dá fome alguma. (Q -17 anos)

Como podemos observar na maioria dos relatos, a principal motivação para o contato dos participantes com comunidades e pessoas pró-anorexia e pró-bulimia é o compartilhamento das experiências, dos conflitos pessoais e a busca de apoio, tanto para continuar a ter controle de si, do corpo e do peso corporal quanto para o auxilio na recuperação. Alguns depoimentos demonstraram uma tensão entre a necessidade de emagrecer e a consciência de estar enfrentando um problema que pode ser superado com apoio de pessoas na mesma situação.

Deste modo, a formação de grupos pró-transtornos alimentares e o próprio contato com pessoas favoráveis a estas práticas seriam os meios que estes indivíduos encontram para expor suas vozes sem serem recriminados.

Através destas formas de entendimento e exposição de si, a anorexia e a bulimia ganham outros significados que ultrapassam o campo das classificações elaboradas pela biomedicina. No entanto, tais concepções não se desligam completamente desse discurso de origem. Os entrevistados têm ciência de que os transtornos alimentares são socialmente considerados doenças, tanto que costumam denominar seus comportamentos como "anoréxicos" e/ou "bulímicos" de acordo com as representações sociais acerca das características gerais da anorexia e da bulimia. Além disso, procuram ilustrar a filiação a tais práticas, como os exemplos de como costumam provocar vômito ou "miar" após a ingestão de comida e como são praticados os episódios de restrição total (no food) ou parcial (low food) da alimentação.

Se a fala desses sujeitos é produto da relação entre a experiência individual e de modelos sociais, não é de se estranhar a incorporação das concepções socioculturais sobre gordura, doença, vida "saudável", beleza e "boa forma". Afinal, vivemos em uma sociedade 
em que a gordura é abominada e tratada como algo que pode ocasionar doenças e levar à morte.

Tal perspectiva aliada à supervalorização do discurso biomédico e da aparência física como um objeto de status e "bem estar", torna-se fundamental para a compreensão da perspectiva que define a anorexia e a bulimia como práticas oriundas de um estilo de vida, que buscam se distanciar de uma interpretação dominante que se apoia nas noções de patologia, doença mental e comportamento desviante (ORTEGA, 2008).

Neste sentido, o contato com pessoas favoráveis a estas práticas de modificação do corpo não só atua na difusão e reprodução de técnicas ou informações a respeito, como ainda se transforma em um mecanismo de entendimento, de compreensão, de ação e de apoio (positivo ou negativo) para aqueles que se encontram nesta situação.

Em relação ao tratamento médico, as concepções acerca da anorexia e da bulimia destacadas expressam os conflitos subjetivos que se relacionam com o modo como é iniciado o tratamento e todo este processo. O tratamento seria um processo crítico e doloroso, e nem sempre obtém resultados satisfatórios.

Foram meus pais que descobriram que eu estava doente e decidiram começar o tratamento! [P: Há quanto tempo você iniciou o tratamento?] Eu consegui parar com o tratamento aos 15 anos. [...] Não foi fácil, ainda hoje fico um pouco preocupado se ganho uns quilos a mais! Mas nada como antigamente. [...] Meus pais ficavam acordados de madrugada para ver se eu estava respirando de tão magro que eu estava! E também junto com a nutricionista eu consegui ir aumentando minha alimentação. [P: Quais eram os aspectos mais difíceis do tratamento?] Saber que todo mundo iria ficar no meu pé. Saber que se eu não assumisse primeiro para mim e depois para os meus pais, eu não conseguiria superar isso. Era uma luta constante sobre o meu eu contra a minha imagem. (C - 19 anos)

Fiz tratamento por 4 anos e meio. Tive bulimia e anorexia. Digo que fiquei um tempo controlado. Hoje em dia, por muitas e muitas vezes, volto a vomitar depois que como ou não me alimento. Tomo inibidores de apetite. [P: Você iniciou o tratamento por conta própria?] $\mathrm{Na}$ verdade, no início minha mãe obrigou a fazer, mas com o passar do tempo fui me acostumando e até gostava. Chegou uma hora que eu não comia mais. E mesmo sem comer tomava água e vomitava. Por conta da falta de comida, tive que, por algumas vezes, ir para o hospital. Foi então que minha mãe decidiu procurar ajuda médica. [...] Eu tinha uns 12/13 anos mais ou menos. [P: Como foi o tratamento? Poderia descrevê-lo?] No início houve uma certa rejeição de minha parte. Depois que comecei a fazer amizade com os médico foi mais tranquilo (pelo menos era o que pensava). Quando vi que o tratamento estava dando resultado, ou seja, que eu estava ganhando peso, me neguei a voltar aos médicos e entrei em depressão. Então, com a depressão, bulimia e anorexia, tentei suicídio por muitas vezes. E isso em um espaço de tempo muito curto, mais ou menos de um ano. Então, com uns 14 anos de idade, talvez um pouco menos, tomava 9 comprimidos antidepressivos e alguns que na verdade nem sabia para que servia por dia. Nesta 
época me sentia tão gordo, tão feio que não queria ver ninguém. Para você ter uma ideia, para eu ir ao banheiro fazer minhas necessidades minha mãe, pai, irmã ou empregada tinham que sair de casa e deixar a casa completamente vazia. Isso servia também para o banho. Fiquei um ano trancado no meu quarto sem ver ninguém. [...] Tomava laxantes que ocasionou um problema no meu intestino. Durante um bom tempo tudo o que eu comia, eu tinha que ir quase que imediatamente ao banheiro, pois descia tudo. Não me lembro o nome certo agora, mas fiquei um bom tempo sem poder comer nada fora de casa ou que não tivesse um banheiro por perto. Foi na época que ganhei algum peso com o tratamento que tentei suicídio. [...] É bom falar sobre isso e dói ao mesmo tempo. ( $\mathrm{P}$ - 20 anos)

Tive anorexia aos 16 anos. "[P: Você iniciou o tratamento por conta própria?] Na verdade por que meus pais me obrigaram, depois de verem a situação em que eu estava. Tive que acabar aceitando o tratamento. [...] Eu me via enorme no espelho. Então, para perder peso eu aderi ao álcool. Sendo assim, sempre que sentia fome eu bebia e no tratamento senti falta, muita mesmo. Acho que entrei em estado de dependência. Essa foi a parte difícil. A vontade de emagrecer era absurda e a vontade de beber era igual. Então, não encontrei mais o que me fazia emagrecer e o que me deixava com uma sensação de realização. Hoje, eu bebo, mas não sou dependente como antes. (S - 19 anos)

Estes trechos demonstram o sofrimento dos entrevistados em abandonar um comportamento tido como desviante e patológico, aliado a outros que têm o mesmo valor simbólico, como a depressão, o vício em álcool, o uso de medicamentos em excesso. Com isso, estes sujeitos sofrem por não se sentirem enquadrados socialmente num modelo de aparência física, e ainda por estarem na condição de desviantes que precisam se adaptar às regras e valores atrelados, não só às concepções de saúde como às questões de ordem sociocultural das quais os sistemas de classificação, diagnóstico e tratamento médico estão imersos. As experiências relatadas apresentam como as manifestações corporais e subjetivas de dor e sofrimento estão inseridas em um universo de referências simbólicas dadas pela própria sociedade. Algo que é visto como tão singular e individual, como estes sentimentos, são exemplo da complexa relação entre o individuo e a sociedade. Daí a noção de que o mundo social existe apenas ao se constituir como sentido para os indivíduos que nele vivem (SARTI, 2001).

Se as concepções relacionadas às manifestações das emoções, dos sentimentos e suas expressões são culturalmente tidas como domínio do feminino, “[...] a racionalidade como algo de masculino, as emoções e os sentimentos enfraquecem as chances das pessoas, e dos homens em particular, no jogo social" (VALE DE ALMEIDA, 1996, p. 15).

No caso dos homens com transtornos alimentares, o ato de falar sobre si, sobre seus sentimentos e suas dores encontra algumas barreiras socioculturais relacionadas à construção do que se espera socialmente ser um comportamento masculino. Isso implica numa 
dificuldade de expressar seus sentimentos, gerando um conflito emocional pelo fato de ser homem, estar insatisfeito com sua aparência corporal e ser qualificado como doente.

\section{Algumas considerações}

A questão da escassez de estudos sobre a anorexia e a bulimia em homens (em comparação com os artigos, pesquisas acadêmicas e textos vinculado à mídia sobre as mulheres) e a baixa procura por tratamento médico foram os principais problemas encontrados na elaboração deste trabalho. Poderíamos atribuir a estas concepções a noção de que a baixa demanda de homens com transtornos alimentares interfere no número de pesquisas e, consequentemente, no interesse sobre o assunto. Entretanto, esta ideia não leva em consideração o modo como os homens são concebidos em nossa cultura, da mesma maneira que não considera o papel da biomedicina, na produção de saberes e na reprodução de valores característicos de um contexto cultural. Outro aspecto importante está na forma com que tais concepções podem ser absorvidas pelo campo institucional, responsável pela elaboração de políticas de acesso à saúde.

Na tentativa de refletir sobre esta problemática, buscaremos finalizar esta discussão apresentando alguns pontos que aproximam as análises dos transtornos alimentares em homens a um debate mais amplo sobre a relação entre masculinidade e saúde. Tais questões podem ser vistas através da produção tardia (a partir da década de 1990) de estudos sobre as masculinidades que retardaram os debates sobre as diferenças existentes neste grupo e, por consequência, a incorporação de novas visões sobre a(s) masculinidade(s) pelo meio social a exemplo da criação de políticas de saúde, como a Política Nacional de Atenção Integral à Saúde do Homem, divulgada em maio de 2009.

No que diz respeito à forma com que os homens lidam (positiva ou negativamente) com o tipo de masculinidade dominante, tal relação pode interferir de diversos modos nos estados de saúde e de doença destes indivíduos, podendo levar à morte (SCHRAIBER; GOMES; COUTO, 2005).

Segundo Gomes, Nascimento e Araújo (2007, p. 565):

Vários estudos constatam que os homens, em geral, padecem mais de condições severas e crônicas de saúde do que as mulheres e também morrem mais do que elas pelas principais causas de morte. Entretanto, apesar de as taxas masculinas 
assumirem um peso significativo nos perfis de morbimortalidade, observa-se que a presença de homens nos serviços de atenção primária à saúde é menor do que a das mulheres.

Dentro desta lógica, os homens estariam aprisionados a um modelo de masculinidade que os privilegia e os obriga a estar de acordo com as representações do que é "ser homem" (no singular) em nossa sociedade. Estes elementos estabeleceriam barreiras na busca e no acesso dos homens à saúde.

Tal concepção se aproxima do questionamento feito por Miguel Vale de Almeida (2000) acerca da dominação masculina: “Até que ponto se pode falar de dominação masculina e até que ponto os agentes dessa dominação não são eles também vítimas dela?” (VALE DE ALMEIDA, 2000, p. 16). Esta questão sugere um exame sobre os aspectos da dominação masculina e de suas implicações na formação e agência dos sujeitos.

As concepções dominantes acerca do que é tido como "feminino" e "masculino" estão presentes nos discursos dos sujeitos através da associação das mulheres à ideia de "cuidado" (de si e do outro) e dos homens às noções sobre "invulnerabilidade", "força" e "virilidade", consideradas:

Características incompatíveis com a demonstração de sinais de fraqueza, medo, ansiedade e insegurança representada pela procura aos serviços de saúde, o que colocaria em risco a masculinidade e aproximaria o homem das representações de feminilidade (GOMES; NASCIMENTO; ARAÚJO, 2007, p. 569).

Decerto que os questionamentos feitos pelos movimentos feminista e LGBT (Lésbicas, Gays, Bissexuais e Transgêneros) abalaram este ideal de homem (viril, forte, invulnerável e provedor) e possibilitaram o surgimento de outras perspectivas de gênero. No entanto, os estudos que se debruçaram sobre os aspectos de estilo de vida "saudável" e de promoção à saúde masculina continuam sendo inferiores às análises sobre as mulheres e seus cuidados com a saúde como, por exemplo, os assuntos relacionados à reprodução feminina, à menstruação, à menopausa, ao aborto, à violência doméstica, etc.

Muitas vezes, as discussões sobre saúde e gênero não abordam diretamente as questões masculinas (SCHRAIBER; GOMES; COUTO, 2005), tendem a recortes particulares (nos campos da sexualidade e da reprodução) ou focam no processo adoecimento e no acesso aos serviços sem contextualizá-los numa ótica das necessidades e especificidades deste grupo. 
Schraiber et al. (2010) fazem uma crítica ao modo como a biomedicina trata de maneira reducionista os aspectos atrelados às necessidades e às especificidade de gênero. $\mathrm{A}$ ideia de "redução" examinada pelos autores está associada ao olhar do médico que se concentra em

[...] diagnosticar as carências do corpo, cuja referência mecânica as situa enquanto lesões anatômicas. Instala-se a primazia da anatomo-patologia na leitura e enunciação das necessidades, em detrimento da consubstancialidade do corpo com as dimensões humanas do emocional, do subjetivo e do interativo (SCHRAIBER et al, 2010, p. 962).

Numa perspectiva ligada a esta prática médica, as desigualdades de gênero, o contato entre o exercício das masculinidades e o adoecimento ou o sofrimento são dimensões ausentes nos serviços de saúde e nas demandas mais valorizadas pelos usuários.

A análise dos autores também aponta algumas dificuldades encontradas pelos homens na procura por serviços de saúde. Dentre estas dificuldades estão: o retardo na busca por assistência médica, que só é feita quando os homens não conseguem mais lidar com seus sintomas; a procura tardia por tratamento que valoriza as práticas de cura, deixando de lado as orientações preventivas; a dificuldade dos homens em aceitarem que são portadores de necessidades quando percebem alguma doença instalada ou quando sentem dor; a "objetividade" presente no discurso médico durante consulta que atenta para as informações voltadas estritamente para os sintomas e os sinais da doença; a ideia de que os homens não "se ajustam ou cabem" a determinados contextos do serviço de saúde.

Os serviços de saúde não conseguem absorver todas as situações cotidianas relacionadas às doenças e aos estilos de vida. Em alguns casos, estes tipos de estado físico e/ou emocional tendem a ser banidos, como:

[...] demandas relacionadas ao abuso de álcool ou drogas, à violência urbana ou doméstica, ou a sofrimentos ou doenças psiquiátricas. Diante desses problemas, recusam-nos como de suas competências na atenção primária, quase sempre argumentando que deveriam ser referidos a serviços especializados (SCHRAIBER et al, 2010, p. 967).

Outro ponto a ser destacado diz respeito à forma como a medicalização e o modelo hegemônico de masculinidade desqualificam e negam determinados carecimentos aos homens. Reforço que se apresenta de maneira inversa sobre o corpo das mulheres. Este modo de reprodução tradicional do feminino e do masculino seria uma das limitações à promoção 
de saúde, visto que não acompanha as necessidades e nem as especificidades de cada grupo, como podemos observar no caso dos transtornos alimentares em homens.

Sendo assim, o contato com outras formas de entendimento acerca dos fenômenos discutidos neste artigo nos permite repensar os limites das análises realizadas no campo dos transtornos alimentares; e ainda apontar outros caminhos para que algumas mudanças possam ocorrer, principalmente, na vida dos sujeitos que lidam com esta experiência.

\section{Referências bibliográficas:}

ANDRADE, Thais Fonseca de; SANTOS, Manoel Antonio dos. "A experiência corporal de um adolescente com transtorno alimentar". Revista Latinoamericana de Psicopatologia Fundamental, v. 12, n. 3, p. 454-468, set. 2009.

BOURDIEU, Pierre. "A gênese dos conceitos de habitus e de campo". In: BOURDIEU, Pierre. O poder simbólico. Rio de Janeiro: Bertrand Brasil, 2000, p. 59-73.

CARLAT, DJ.; CAMARGO JR., CA; HERZOG, D. "Eating disorders in males: a report on 135 patients”. American Journal of Psychiatry, v. 154, n. 8, p. 1127- 1132, 1997.

CLAUDINO, Angélica de Medeiros; BORGES, Maria Beatriz Ferrari. "Critérios de diagnósticos para os transtornos alimentares: conceitos em evolução". Revista Brasileira de Psiquiatria, v. 24, Suplemento III, p.07-12, 2002.

CONNELL, Robert William. Masculinities: knowledge, power and social change. California: University of California Press, 1995.

CONRAD, Peter. The medicalization of society: on the transformation of human conditions into treatable disorders. Baltimore: Johns Hopkins University, 2007.

DAVIES, Deirdre. "Health and the discourse of weight control". In: PETERSEN, Alan; WADDELL, Charles. Health matters: a sociology of illness, prevention and care. Buckingham: Open University, 1999.

DOUGLAS, Mary. Pureza e perigo. São Paulo: Perspectiva, 1976.

ELIAS, Norbert. O processo civilizador I: uma história dos costumes. Rio de Janeiro: Zahar, 1990.

GOMES, Romeu; NASCIMENTO, Elaine Ferreira do.; ARAÚJO, Fábio Carvalho de. "Por que os homens buscam menos os serviços de saúde do que as mulheres? As explicações de 
homens com baixa escolaridade e homens com ensino superior". Cadernos de Saúde Pública, v. 23, n. 3, 2007, p. 565-574.

HERTZ, Robert. "A preeminência da mão direita: um estudo sobre a polaridade religiosa". Religião e Sociedade. Rio de Janeiro: Tempo e Presença, n. 6, 1980, p. 99-128.

KIMMEL, Michael; MESSNER, Michael. Men's Lives. Boston: Ally and Bacon, 1998.

KIMMEL, Michel. "A produção simultânea de masculinidades hegemônicas e subalternas". Horizontes Antropológicos, ano 4, n. 9, 1998, p. 103-117.

LAPLANTINE, François. "Antropologia dos sistemas de representações da doença: sobre algumas pesquisas desenvolvidas na França contemporânea reexaminadas à luz de uma experiência brasileira". In: JODELET, Denise (Org.). As representações sociais. Rio de Janeiro: Eduerj, 2001, p. 241-259.

LIRA, Luciana Campelo de. Narrativas de Ana: corpo, consumo e self em um grupo próanorexia na internet, 2004. Dissertação (Mestrado em Antropologia), Programa de PósGraduação em Antropologia, UFPE, Pernambuco - PE.

MELIN, Paula; ARAÚJO, Alexandra M. "Transtornos alimentares em homens: um desafio diagnóstico”. Revista Brasileira de Psiquiatria, v. 24, Suplemento III, p.73-76, 2002.

MELO, Mariana Leite de. Dois pesos e duas medidas: 'ser gorda' e os vigilantes do peso, 2004. Dissertação (Mestrado em Ciências Sociais), Programa de Pós-Graduação em Ciências Sociais, UERJ, Rio de Janeiro - RJ.

MISKOLCI, Richard. "Corpos elétricos: do assujeitamento do sujeito à estética da existência”. Estudos Feministas, n. 3, v. 14, p. 681-693, 2006.

MORGAN, Christina M; VECCHIATTI, Ilka Ramalho; NEGRÃO, André Brooking. "Etiologia dos transtornos alimentares: aspectos biológicos, psicológicos e socioculturais". Revista Brasileira de Psiquiatria, v. 24, Suplemento III, p.18-23, 2002.

MOTTA, Maria. "De Vênus a Kate Moss: reflexão sobre corpo, beleza e relações de gênero". 2007, p. 01-11. Disponível em: http://fido.palermo.edu/servicios dvc/encuentro2007/02 auspicios publicaciones/actas deseno/articulos pdf/A009.pdf. Acesso em: 13 dez. 2008.

ORTEGA, Francisco. "Práticas de ascese corporal e constituição de bioidentidades". Cadernos de Saúde Coletiva, v. 11, n.1, p. 59-77, 2003.

SABINO, Cesar. "Musculação: expansão e manutenção da masculinidade". In: GOLDENBERG, Mirian (Org.). Os novos desejos: das academias de musculação às agências de encontros. Rio de Janeiro e São Paulo: Record, 2000, p. 61-103.

SARTI, Cynthia. “A dor, o indivíduo e a cultura”. Saúde e Sociedade, v. 10, n. 1, 2001, p. 03-13. 
SCHRAIBER, Lília Blima; GOMES, Romeu; COUTO, Márcia Thereza. "Homens e saúde em pauta da Saúde Coletiva". Ciência \& Saúde Coletiva, v. 10, n. 1, 2005, p. 07-17.

SCHRAIBER, Lília Blima; FIGUEIREDO, Wagner dos Santos; GOMES, Romeu; COUTO, Márcia Thereza; PINHEIRO, Thiago Félix; MACHIN, Rosana; SILVA, Geórgia Sibele Nogueira da; VALENÇA, Otávio. "Necessidades de saúde e masculinidades: atenção primária no cuidado aos homens". Cadernos de Saúde Pública, v. 26, n. 5, 2010, p. 961970.

SILVA, Ana Beatriz. Mentes insaciáveis - anorexia, bulimia e compulsão alimentar. Rio de Janeiro: Ediouro, 2005.

SOARES, Ana Helena Rotta; ARAGÃO, Priscila Menezes de. "Ame não o que você é, mas o que você pode se tornar: a identidade da rede pró-ana e pró-mia na internet". Polêmica: Revista Eletrônica, Rio de Janeiro, p. 01-05, 2006. Disponível em: http://www.seuabrigo.com.br/docs/estudio_polemica.pdf. Acesso em: 31/05/2013.

SOPHIA, Bianca de Vasconcellos. O movimento pró-anorexia e pró-bulimia na Internet: uma reflexão sobre as práticas alimentares, saúde e doença, corpo e identidade, 2009. Monografia (Graduação em Ciências Sociais), Instituto de Filosofia e Ciências Humanas, UERJ, Rio de Janeiro - RJ.

Quando a magreza torna-se um ideal masculino: um estudo socioantropológico sobre a anorexia e a bulimia em homens, 2011. Dissertação (Mestrado em Ciências Sociais), Programa de Pós-Graduação em Ciências Sociais, UERJ, Rio de Janeiro - RJ.

VALE DE ALMEIDA, Miguel. Senhores de si: uma interpretação antropológica da masculinidade. Portugal: Fim de Século, 2000.

"Gênero, masculinidade e poder: revendo um caso do Sul de Portugal". Anuário Antropológico/95. Rio de Janeiro: Tempo Brasileiro, 1996, p. 161-190. 


\title{
WHEN THINNESS BECOMES A MASCULINE IDEAL: A SOCIO ANTHROPOLOGICAL VIEW OF EATING DISORDERS IN MEN
}

\begin{abstract}
This paper aims to discuss the emergence of cases of anorexia and bulimia in men and its relation to: a) socio-cultural issues related to the cult of thinness and its consequences (like the notion of lifestyle), and b) discussions about masculinity and bodily and subjective experiences of these subjects. Its main objective is to understand how anorexia and bulimia, seen as psychiatric disorders in the medical literature, are not restricted only to females, also suggesting implications related to the drafting of biomedical knowledge, their fields of research and action. The methodology employed was to conduct interviews via MSN Messenger, with 20 men between 13 and 30 years old, who claim going or have gone through some kind of experiment involving anorexia and / or bulimia.
\end{abstract}

KEYWORDS: Gender; eating disorders; medical anthropological. 